\title{
Dynamic Fiscal Competition with Public Infrastructure Investment: Austerity and Attracting Capital Inflow
}

\author{
Yang Chen ${ }^{*}$, Weihong Huang ${ }^{2}$, Simon Rudkin ${ }^{3}$ \\ ${ }^{1}$ International Business School Suzhou, Xi'an Jiaotong-Liverpool University, Suzhou, China \\ ${ }^{2}$ Economics Division, SSS, Nanyang Technological University, Singapore \\ ${ }^{3}$ Swansea University, Singleton Park, Swansea, UK \\ Email: *yang.chen@xjtlu.edu.cn, awhhuang@ntu.edu.sg, s.t.rudkin@swansea.ac.uk
}

How to cite this paper: Chen, Y., Huang, W.H. and Rudkin, S. (2018) Dynamic Fiscal Competition with Public Infrastructure Investment: Austerity and Attracting Capital Inflow. Theoretical Economics Letters, 8, 2460-2478.

https://doi.org/10.4236/tel.2018.811159

Received: June 29, 2018

Accepted: August 19, 2018

Published: August 22, 2018

Copyright (C) 2018 by authors and Scientific Research Publishing Inc. This work is licensed under the Creative Commons Attribution International License (CC BY 4.0).

http://creativecommons.org/licenses/by/4.0/

\begin{abstract}
In a global economy characterised by austerity, regionalisation and bidding for mobile capital, fiscal competition models have a major contribution to make to the economic development debate. With labour proving immobile, even within borderless regions like the European Union, our extension of static models into a dynamic setting offers invaluable advice for policymakers. This paper presents the effects of fiscal competition, considering the inter-temporal interactions among the economic activity of firms, capital taxation and public infrastructure investment in a small-open economy. Four cases emerge, but most interestingly public and private capital being substitutes allows reductions in the net tax burden alongside infrastructure accumulation provided public capital is not too productive. We also review factor complementarity, where subsidies become attractive. Transitional impacts depend on the marginal product of public capital. Hence, from the first case, our model addresses the apparent puzzle of high infrastructure accompanying low taxation, and does so without imposing limitations on competition.
\end{abstract}

\section{Keywords}

Dynamic Fiscal Competition, Infrastructure Investment

\section{Introduction}

Post global financial crisis the world economy can be classified as one of regionalisation, budgetary responsibility and organisation against the forces of globalisation that dominated recent economic history. Mobility of capital remains 
high, and governments seek to ensure this is attracted to their jurisdiction through competitive taxation rates and other suitable incentives. Inevitably this means public spending must fall, or the burden be shifted onto less mobile production factors like labour. If nations can regionalise and agree to co-operation, then the large market is attractive to firms and there is no race to the bottom of the type predicted by most taxation competition models in the mould of [1] or [2] - a combination henceforth referred to as ZMW. However, as [3] [4] [5] and others, note incentives to compete dominate the search for harmonisation in Europe, despite attempts to harmonise taxes ${ }^{1}$ the community still sees competition between nations and a race to the bottom in all aspects of government policy. This is exactly as cautioned on early evidence by [6]. Hence whilst the global position may have evolved immeasurably, and solutions to the suboptimal low public spending problem have been sought since the early works, fiscal competition remains as relevant today as always.

Oates (1973) nicely summarises fiscal competition "is not just a matter of influencing the decisions of a particular firm here or there, but rather that of establishing a favourable business climate the extent and condition of the transportation system, the quality of local schools and the general structure and level of local taxes all influence business location". Focus in the static taxation competition literature has thus fallen on the mobile factors, particularly capital, while the burden moves to immobile factors such as labour, with the result that capital tax rates, and public good provision, are too low. Despite several fruitful extensions [7] [8] [9] the results remain limited by the key problem of a lack of time dimension. Results also fail to support observations that falling tax rates [10] have accompanied increased public infrastructure investment with improved quality [11]. However the unifying suggestion is that reducing competition, be that through co-operation as in the EU, promoting home country bias [12], or the existence of trading costs [13], can allow jurisdictions to get closer to socially optimal tax rates and public good provisions. [14] reviews the welfare costs of tax competition, noting that even co-operating jurisdictions do not achieve efficiency. Empirical evidence meanwhile points to governments competing on many dimensions ${ }^{2}$, a seeming tension between theory and policy emerges.

Where the static framework falls down is in its inability to account for feedback from taxation rates to the future investment environment. An attempt to link within a period is made by [16] who consider that infrastructure is tailored to individual firm needs and therefore can be thought of as a location in infrastructure space with no attention given to the level provided. Though early overlapping generations models [2] [9] bring dynamic analysis, they necessarily ignore many of the externalities present in fiscal competition. One such example ${ }^{1}$ Examples of tax harmonization quoted in [5] include the requirement for all EU nations to impose Value Added Tax (VAT) and the common consolidated corporate tax base (CCCTB), which states that one nation should impose taxation upon multi-national corporations and then reallocates corporation's tax liability across the nations in which they do business.

${ }^{2}$ [15] study of German regional tax variation fits our small open economy framework well and illustrates how key neighbouring tax rates are to determining domestic rates. 
is the feedback of capital stock size to interest rates through inter-temporal savings decisions [17] [18]. Equally capital can be thought of as a stock variable when dynamics are introduced, and again provide feedback to local economies [12]. Each of these papers puts forward potential for taxation to be too high, therefore reversing the race to the bottom conclusion of earlier work. However, unlike our work, all neglect the role of infrastructure and the other factors which attract capital investment.

As suggested by [19] and DWZ public sector spending corresponds to expenditure items such as infrastructure roads, sewers and the like or general training expenditures, all of which feed back into corporate profits and general well-being. [20] introduce this to the tax competition literature with a three stage game that allows countries to choose investment before competing in tax rate to win investment, making a high level of spending a norm alongside the low tax rate. Precisely this is observed in Eastern Europe [21]. Overprovision of infrastructure could be seen as a benefit, making it one of the key suggestions of the economic growth literature for attracting investment [22] [23]. Inevitably the taxation burden rises, immobile factors such as labour footing the bill. Is the bidding to attract large firms a good thing? Indeed can such policies be sustainable?

Two recurring themes in the literature to date are that labour is immobile and that governments therefore pass on tax burdens rather than borrowing. Whilst migration may play strong as a political issue actual levels remain low, even within regions purporting to have free movement of labour like the EU [24] [25]. [26] reinforces that in the European Union "while capital can take advantage of permeable borders, national administrations and organised labour cannot". In the UK, as elsewhere, the post global financial crisis investment position is neatly summarised as "The government' current fiscal plans mean that public finance for infrastructure is tightly constrained" [27]. In essence the UK government, like many others, are reducing borrowing in the age of austerity and will only fund based on taxation revenue. Such rules need not preclude growth or infrastructure expenditure, but there remains a strong sense that their relaxation would help nations attract more investment for growth without a restrictive tax burden [28] [29] [30]. Thus while both immobile labour and exclusion of government borrowing have vocal critics there remains strong evidence these assumptions in our model are empirically supported, especially since the financial crisis.

This paper then contributes to analyse the effects of tax in an open economy where both stocks of private capital and public investment adjust dynamically over time and across jurisdictions. The degree of factor mobility is endogenously determined as a result of optimal behavior by factor users subject to adjustment costs. From an economic development point of view, the dynamic analysis is crucial to an understanding of the time frame over which tax incentives or other development policies can be expected to work, necessarily absent in the static analysis. Previous studies have examined some aspects of inter-temporal fiscal 
competition ${ }^{3}$, though few have explicitly addressed dynamic adjustment of economic resources. Our work is related to [36] and [37], which identify the mobility of capital and labour in a systematic way but not analyse the dynamic effect of tax change on the public infrastructure investment.

Note that there are two directions of causality between public spending and private input. On one hand, the evolution of private inputs and variations in output can directly affect the size of the tax base and therefore the government's capacity to finance new investment on public infrastructure. These concerns highlight the possibility of reverse causality. On the other hand, it is conceivable that public spending can also affect the demand for private inputs, as well as their marginal productivity, production costs, and, finally, the aggregate level of production. This study first models the reverse causality in a dynamic framework where the public infrastructure investment, financed by capital taxes, is assumed to be publicly provided and external to the firm. Public investment directly affects the dynamic optimisation of the firm. We then present the tax effect in the short-, the long-run and the transitional period, considering the positive causality.

This study shows that the system adjusts gradually to a long-run new steady state equilibrium, with effects on equilibrium allocations that depend on the local production technology, cost adjustment technology as well as complementarity of both private and public capital. There is no instantaneous tax effect on the capital stock. The marginal product of capital plays a significant role influencing the inter-temporal tax effects on factor stocks, the shadow values and the return rates.

To illustrate the conclusions of the model a Cobb-Douglas production economy example is provided, allowing one to visualise the effects of fiscal policy change. We exemplify the case in which local capital taxation is increased. If the marginal product of capital is less than one, and public investment complements private investment in the production process, an outflow of private capital follows the change but this is accompanied by a rise in the public infrastructure investment. This fits the narrative of higher infrastructure spending emerging from later studies with limited competition. In the meantime, it decreases the return rate to both public infrastructure investment and immobile labor. Highly productive public investment may however crowd in private investment if the net capital tax rate is competed to the top, a concern not highlighted by static models. A second interesting result is the ability of labour to enjoy the benefits of increased business investment as wages adjust slowly to capital tax cuts. It is thus meaningful, especially in the present global economic climate, to distin-

${ }^{3}$ [31] discusses the problem of time-consistent taxation of mobile capital. [32] develop a two-period model of tax competition in which a pair of governments use debt policy to manipulate the inter-temporal structure of taxation. Dynamic models of fiscal competition with imperfectly mobile households are discussed by [33] and [34]. And it is not uncommon for strategic fiscal competition to be formulated as "stage games" with sequential decision structures e.g. [35], though these typically focus on the determination of a single equilibrium of private and public choices rather than on the evolution of these choices over time. 
guish between perfectly mobile and highly immobile factors of production in empirical study for policy suggestions.

The paper proceeds as follows. The next section presents a dynamic model of a firms' behaviour under costly investment adjustment with joint utilization of private and public funding, leading to an analysis of the dynamic responses of economic resources to the change of capital tax in Section 3. Section 4 provides a numerical example of the first-order dynamic effects of changes in capital taxation within the Cobb-Douglas production technology framework. Section 5 briefly summarizes and discusses further applications and directions for future research.

\section{Competition for Mobile Resources with Costly Dynamic Adjustment}

The focus of attention is a representative small open jurisdiction, the group of which we shall refer to as "countries" though the analysis can just as well be interpreted in terms of horizontal fiscal competition between lower-level governments within a federation. The dynamic model assumes no uncertainty, perfectly competitive markets, and continuous time.

The two imperfectly mobile production inputs $k_{t}$ and $G_{t}{ }^{4}$ are called private and public capital, respectively. $\bar{l}$ denotes the immobile factor of inputs in production. It is termed as labour in the current section for elaboration convenience, though it could be interpreted as land or more specifically as different types of labour. The value of output within the jurisdiction at time $t$ depends on three inputs, and is given by the strictly concave function $f\left(k_{t}, \bar{l}, G_{t}\right)$ which is homogenous of degree 1.

Local producers purchase inputs at prices that are determined in external markets and therefore taken as given within each small economy. Units of measurement may be chosen so that one unit of each input has a price of unity. Capital goods may be thought of as a non-consumption commodity rather similar to the all-purpose numeraire commodity, as in standard macroeconomic and growth models. In the case where input is some type of labour or land, the fixed price could be interpreted as the externally-given net wage rate or net land return rate. Following [38], we assume that public and private capital are complements when $f_{k_{t} G_{t}}>0$.

The private capital stock evolves over time according to $\dot{k}=\left(i_{t}-\bar{\delta}\right) k_{t}$, where $i_{t}$ is the investment rate and $\bar{\delta}$ is the constant depreciation rate. Public capital is modelled as the accumulated tax revenues where $G_{t}=\bar{T}+\bar{\tau} k_{t}$, with $\bar{T}$ denotes the lump-sum taxes imposed by the local government on the household, who supplies one unit of a non-traded input called "labour" at each moment. $\bar{\tau}$ is the time-invariant capital tax rate ${ }^{5}$. We do not allow inter-jurisdictional

${ }^{4}[1]$ denotes $G$ as the level of publicly provided services to businesses as an intermediate produce good.

${ }^{5}$ The time invariance assumption of fiscal policy greatly simplifies the analysis but also restricts application to individual rate change decisions. 
borrowing, or lending, to preserve tractability and in line with the current austerity drive. $\bar{\tau}$ and $\bar{T}$ can be negative, corresponding respectively to the subsidy and public expenditures on transfer payments or their equivalent. The public input thus evolves according to $\dot{G}=\bar{\tau} \dot{k}$.

At each point in time, a representative firm chooses the optimal investment rate $i_{t}$ to maximize its net present value of all future cash flows. The cash flow at time $t$ is the value of its output, less the wage payment to workers, the borrowing cost to capital, tax costs, its expenditures on investment and the associated adjustment cost in investment ${ }^{6}$. The adjustment cost is measured by function $c\left(i_{t}\right) k_{t}$, assumed to be nonnegative, strictly increasing, and strictly convex in the rate of investment $i_{t}$, i.e., $c^{\prime}\left(i_{t}\right)>0<c^{\prime \prime}\left(i_{t}\right)$. Also, $c(0)=0$. Note that the firm can borrow from the world market at the given interest rate $\bar{r}$. The dynamic optimisation problem is formulated as (The time subscript $t$ is suppressed herein for simplicity, and labour inputs are normalised to 1),

$$
\begin{gathered}
\max _{i} \Pi=\int_{0}^{\infty}\{f(k, G)-w-(\bar{r}+\bar{\tau}) k-[i+c(i)] k\} \mathrm{e}^{-\bar{r} t} \mathrm{~d} t \\
\text { s.t } \dot{k}=(i-\bar{\delta}) k \\
\dot{G}=\bar{\tau} \dot{k}
\end{gathered}
$$

where $w$ is the wage rate, and $k_{0}$ is the initially given stock of capital.

Necessary conditions for the maximisation of $\Pi$ subject to the evolution equations can be expressed as (See Appendix A for proof of Equations (3)-(6)),

$$
\begin{gathered}
q_{1}+q_{2} \bar{\tau}=1+c^{\prime}(i) \\
w=f(k, G)-f_{k} k-f_{G} G \\
-\dot{q}_{1}=f_{k}-(\bar{r}+\bar{\tau})-i-c(i)-q_{1}(\bar{r}+\bar{\delta}-i)+q_{2} \bar{\tau}(i-\bar{\delta}) \\
\dot{q}_{2}=\bar{r} q_{2}-f_{G}
\end{gathered}
$$

where $q_{1}$ and $q_{2}$ denote the shadow prices of private and public inputs, respectively, in units of contemporaneous output. They summarise all information about the future that is relevant to a firm's investment decision. A unit increase in the firm's private input in capital stock increases the present value of the firm's profits by $q_{1}$, and a unit increase in the expenditure of publicly provided services raises the firm's value by $q_{2}$. Since we have assumed that the purchase price of inputs is fixed at $1, q_{1}$ is well known as Tobin's $q$ [39] and $q_{2}$ is similarly the market value of a unit of public input to its replacement costs.

Equation (3) states that the firm invests to the point where the cost of acquiring capital equals the value of capital. It determines $i$ implicitly as a function of $q_{1}, q_{2}$, and $\bar{\tau}$, i.e, $i=\phi\left(q_{1}, q_{2}, \bar{\tau}\right)$, satisfying $c^{\prime \prime} \phi_{1}^{\prime}=1, c^{\prime \prime} \phi_{2}^{\prime}=\bar{\tau}, c^{\prime \prime} \phi_{\bar{\tau}}^{\prime}=q_{2}$.

The evolution equations of $k$ and $G$ plus (5) and (6) form a 4-equation dynamic system in the variables $\left(k, q_{1}, G, q_{2}\right)$ :

${ }^{6}$ Examples of such adjustment costs are the costs of installing new capital and training workers to operate the new machines. 


$$
\begin{gathered}
\dot{k}=(i-\bar{\delta}) k \\
-\dot{q}_{1}=f_{k}-(\bar{r}+\bar{\tau})-i-c(i)-q_{1}(\bar{r}+\bar{\delta}-i)+q_{2} \bar{\tau}(i-\bar{\delta}) \\
\dot{G}=\bar{\tau}(i-\bar{\delta}) k \\
-\dot{q}_{2}=f_{G}-\bar{r} q_{2} .
\end{gathered}
$$

Let $i^{*}, k^{*}, G^{*}, q_{1}^{*}, q_{2}^{*}$ denote the steady state values. Equation (7), Equation (8) and Equation (10) imply that,

$$
\begin{gathered}
i^{*}=\bar{\delta} \\
f_{k^{*}}=\bar{r}+\bar{\tau}+\bar{\delta}+c(\bar{\delta})+\bar{r} q_{1}^{*} \\
f_{G^{*}}=\bar{r} q_{2}^{*}
\end{gathered}
$$

which uniquely determine the steady state of the system.

\section{Tax Impacts on Mobile Resources: Short Run, Long Run, and Transitional}

\subsection{Comparative Dynamics}

In order to see how the change in tax affects the equilibrium private and public input, we first derive the variational equations. Assuming the system is initially in equilibrium, the system of variational equations can be expressed as below ${ }^{7}$

$$
\left[\begin{array}{c}
\mathrm{d} \dot{k} / \mathrm{d} \bar{\tau} \\
\mathrm{d} \dot{q}_{1} / \mathrm{d} \bar{\tau} \\
\mathrm{d} \dot{G} / \mathrm{d} \bar{\tau} \\
\mathrm{d} \dot{q}_{2} / \mathrm{d} \bar{\tau}
\end{array}\right]=\left[\begin{array}{cccc}
0 & k^{*} / c^{\prime \prime} & 0 & k^{*} \bar{r} / c^{\prime \prime} \\
-f_{k k}^{*} & \bar{r} & -f_{k G}^{*} & 0 \\
0 & k^{*} \bar{\tau} / c^{\prime \prime} & 0 & k^{*} \bar{\tau}^{2} / c^{\prime \prime} \\
-f_{k G}^{*} & 0 & -f_{G G}^{*} & \bar{r}
\end{array}\right]\left[\begin{array}{c}
\mathrm{d} k / \mathrm{d} \bar{\tau} \\
\mathrm{d} q_{1} / \mathrm{d} \bar{\tau} \\
\mathrm{d} G / \mathrm{d} \bar{\tau} \\
\mathrm{d} q_{2} / \mathrm{d} \bar{\tau}
\end{array}\right]+\left[\begin{array}{c}
k^{*} f_{G}^{*} /\left(\bar{r} c^{\prime \prime}\right) \\
1 \\
\bar{\tau} k^{*} f_{G}^{*} /\left(\bar{r} c^{\prime \prime}\right) \\
0
\end{array}\right]
$$

We use $f_{i j}^{*}=\left.\frac{\partial^{2} f}{\partial i \partial j}\right|_{(k, G)=\left(k^{*}, G^{*}\right)}(i, j=k, G)$ to denote the value of second order partial derivative $f_{i j}$ at the steady state.

As $\mathrm{d} k / \mathrm{d} \bar{\tau}$ and $\mathrm{d} g / \mathrm{d} \bar{\tau}$ are linearly dependent, the reduced-form dynamic system is:

$$
\left[\begin{array}{c}
\mathrm{d} \dot{k} / \mathrm{d} \bar{\tau} \\
\mathrm{d} \dot{q}_{1} / \mathrm{d} \bar{\tau} \\
\mathrm{d} \dot{q}_{2} / \mathrm{d} \overline{\bar{\tau}}
\end{array}\right]=\left[\begin{array}{ccc}
0 & k^{*} / c^{\prime \prime} & k^{*} \bar{r} / c^{\prime \prime} \\
-f_{k k}^{*} & \bar{r} & 0 \\
-f_{k G}^{*} & 0 & \bar{r}
\end{array}\right]\left[\begin{array}{c}
\mathrm{d} k / \mathrm{d} \bar{\tau} \\
\mathrm{d} q_{1} / \mathrm{d} \bar{\tau} \\
\mathrm{d} q_{2} / \mathrm{d} \bar{\tau}
\end{array}\right]+\left[\begin{array}{c}
k^{*} f_{G}^{*} /\left(\bar{r} c^{\prime \prime}\right) \\
1 \\
0
\end{array}\right]
$$

The necessary stability condition requires the determinant of the parameter matrix to be negative [41], that is,

$$
\frac{1}{c^{\prime \prime}} r k^{*}\left(\bar{\tau} f_{k G}^{*}+f_{k k}^{*}\right)<0
$$

Let $\lambda_{i}(i=1,2,3)$ be the eigenvalues of the characteristic matrix. They are respectively,

$$
\lambda_{1}=\bar{r}
$$

${ }^{7}$ See [40] and Appendix B for details. 


$$
\begin{aligned}
& \lambda_{2}=\frac{1}{2} \bar{r}-\frac{1}{2} \sqrt{\bar{r}^{2}-4 \frac{\bar{\tau}}{c^{\prime \prime}} k^{*} f_{k G}^{*}-\frac{4}{c^{\prime \prime}} k^{*} f_{k k}^{*}} \\
& \lambda_{3}=\frac{1}{2} \bar{r}+\frac{1}{2} \sqrt{\bar{r}^{2}-4 \frac{\bar{\tau}}{c^{\prime \prime}} k^{*} f_{k G}^{*}-\frac{4}{c^{\prime \prime}} k^{*} f_{k k}^{*}}
\end{aligned}
$$

where $\lambda_{1}$ and $\lambda_{3}$ are positive while $\lambda_{2}$ is negative. Using the boundary conditions $\mathrm{d} k_{0} / \mathrm{d} \bar{\tau}=0$ and $\lim _{t \rightarrow \infty} \mathrm{d} k(t) / \mathrm{d} \bar{\tau}=\mathrm{d} k^{*} / \mathrm{d} \bar{\tau}$, which describe the short-run and long-run effects of the change in tax on the level of private capital employed in the local economy, we derive the solutions to the dynamic system. The dynamic responses of economic resources to the change in capital tax rate are given by (see Appendix C):

$$
\begin{gathered}
\mathrm{d} k / \mathrm{d} \bar{\tau}=\frac{\left(1-f_{G}^{*}\right)\left(1-\mathrm{e}^{\lambda_{2} t}\right)}{\bar{\tau} f_{G k}^{*}+f_{k k}^{*}} \\
\mathrm{~d} G / \mathrm{d} \bar{\tau}=\frac{\bar{\tau}\left(1-f_{G}^{*}\right)\left(1-\mathrm{e}^{\lambda_{2} t}\right)}{\bar{\tau} f_{G k}^{*}+f_{k k}^{*}} \\
\mathrm{~d} q_{1} / \mathrm{d} \bar{\tau}=-\frac{\lambda_{3} / \bar{r}\left[\bar{\tau} f_{G k}^{*}+f_{G}^{*} f_{k k}^{*}\right]+\left(1-f_{G}^{*}\right) f_{k k}^{*} \mathrm{e}^{\lambda_{2} t}}{\lambda_{3}\left(\bar{\tau} f_{G k}^{*}+f_{k k}^{*}\right)} \\
\mathrm{d} q_{2} / \mathrm{d} \bar{\tau}=\frac{\left(1-f_{G}^{*}\right)\left(1-\bar{r} \mathrm{e}^{\lambda_{2} t} / \lambda_{3}\right)}{\bar{r}\left(\bar{\tau} f_{G k}^{*}+f_{k k}^{*}\right)} f_{G k}^{*}
\end{gathered}
$$

The main results are summarised into the table and presented in Proposition 1 as below,

$$
\begin{array}{ccccc} 
& \mathrm{d} k / \mathrm{d} \bar{\tau} & \mathrm{d} q_{1} / \mathrm{d} \bar{\tau} & \mathrm{d} G / \mathrm{d} \bar{\tau} & \mathrm{d} q_{2} / \mathrm{d} \bar{\tau} \\
f_{G}^{*}<1 & - & - & \operatorname{sgn}\left(f_{G k}^{*}\right)=-\operatorname{sgn}(\bar{\tau}) & -\operatorname{sgn}\left(f_{G k}^{*}\right)=\operatorname{sgn}(\bar{\tau}) \\
f_{G}^{*}>1 & + & \text { indeteminate } & -\operatorname{sgn}\left(f_{G k}^{*}\right)=\operatorname{sgn}(\bar{\tau}) & -\operatorname{sgn}\left(f_{G k}^{*}\right)=-\operatorname{sgn}(\bar{\tau})
\end{array}
$$

Proposition 1. Starting from an initial steady-state equilibrium, the impacts of an unanticipated permanent rise in the fiscal burden on capital depend critically on the marginal product of public input at the equilibrium, that is, $f_{G}^{*}$. Specifically,

1) If $f_{G}^{*}<1$, the stock and the market value of private capital will decrease monotonically to its new steady-state value. Providing that both private and public capital are complements, public capital will increase monotonically but its market value will decrease monotonically.

2) If $f_{G}^{*}>1$, the stock of private capital will increase monotonically to its new steady-state value, but its value varies indeterminately. Providing that both private and public capital are complements, the public capital will decrease monotonically but its market value will increase monotonically.

The magnitude of the marginal product of public capital directly affects the impact of tax policy on the evolution of capital and indirectly impacts the economic performance. In the empirical literature pioneered by [42] and [43], the estimate of elasticity of output with respect to public capital ranges between 0.34 
and 0.39 using a production function approach relating output, employment, and private capital as well as public capital. These estimates were interpreted as implying an annual marginal productivity of public capital of about 70 cents on the dollar. [44] reports that in the long term, aggregate public investment crowds in private investment and has a positive effect on private output with a long-term accumulated marginal product of $\$ 4.46$, which corresponds to a rate of return of $7.8 \%$, a result that is at least three times smaller than the one initially estimated by [42]. Moreover, while there is little consensus in the empirical evidence about the magnitudes of the effects of public investment, there is also little doubt that they are positive and significant.

At $t=0$, these expressions shown in Equations (20)-(23) are equal to 0, corresponding to a "short-run" in which no resources are mobile. As $t \rightarrow \infty$, the dynamic model describes, at its extreme, a "long-run" defined to be a steady state in which factor stocks are unchanging over time; equilibrium stocks of mobile resources adjust exactly as predicted in the static tax competition model with two possible results-race to the bottom if $f_{G}^{*}<1$ and race to the top if $f_{G}^{*}>1$. These definitions of "short" and "long" run appear to be the natural counterparts, in a dynamic model, "initial" and "new" equilibria that comparative static analyses are intended to describe. While understanding the short and long run effects of policy changes are positively and normatively important, much of the significant impact of policy occurs during the transition from the short to the long run. From the characteristic roots of the system derived from Equation (18) the equilibrium adjustment speed depends on the adjustment cost technology and the properties of the production technology.

Proposition 1 indicates the signs of $\mathrm{d} k / \mathrm{d} \bar{\tau}, \mathrm{d} q_{1} / \mathrm{d} \bar{\tau}, \mathrm{d} G / \mathrm{d} \bar{\tau}$ and $\mathrm{d} q_{2} / \mathrm{d} \bar{\tau}$ when 1) $f_{G}^{*}<1$ and 2) $f_{G}^{*}>1$. These give the effects of the net capital taxation burden on private capital, its shadow price, infrastructure spending and its shadow prices respectively. By noting that it is possible governments may want to subsidise firms $(\bar{\tau}<0)$ we can motivate the results under taxation or subsidy. How effective any tax, or subsidy, will be depends on whether our two forms of capital are complements or substitutes, and how productive public capital actually is. Impacts are not instantaneous, but play out over time resulting in long run steady states, so all discussion must be qualified with this. Taxation can, should public capital be sufficiently productive, and the two forms of capital be substitutes, be imposed and not lead to capital outflow. Where $f_{G}^{*}<1$ results indicate capital outflow and a fall in public infrastructure. As $f_{G}^{*}<1$ increases above 1 the dynamic effect of fiscal policy on Tobins $q$ in the transition period is ambiguous.

Subsidies by contrast will be rational if the two forms of capital are complements. When public infrastructure is less productive such a subsidy applied for all time, $t>0$, requires matching any reductions in the subsidy would reduce accumulation of private capital, allowing funds to be directed to infrastructure, and hence a lower market value of public capital. However, as public capital becomes more productive the subsidy causes a crowding out of private in- 
vestment.

\subsection{Tax Effect on the Speed of Transitional Dynamics}

In the above subsection, we demonstrated that the transitional effect of fiscal policy depends directly on the equilibrium capital mobility speed denoted by $\lambda$, the economic convergence speed in the growth literature (see [45] for example). Given the economic importance of what happens during the transition to the steady state, it is thus interesting to see how the change in the fiscal burden of capital affects the convergence speed. If the transition is rapid, we can focus on the behaviour at the steady state, where the comparative-dynamic response is discussed and most economies would typically be close. Conversely, if the transition is slow, economies would typically be far from their steady states, and, hence, the comparative-dynamic analysis would be dominated by the transitional dynamics.

Consider a log-linear approximation of the dynamic systemof $\left(k, q_{1}, G, q_{2}\right)$ in the neighborhood of the steady-state ${ }^{8}$. After some calculations and manipulations, the $\beta$-convergence speed is given by:

$$
\begin{aligned}
\beta & =-\mathrm{d} \gamma_{k} / \mathrm{d}\left(\ln k-\ln k^{*}\right)=-\lambda_{2} \\
& =-\frac{1}{2} \bar{r}+\frac{1}{2} \sqrt{-4 \bar{\tau} k^{*} f_{G k}^{*} / c^{\prime \prime}-4 k^{*} f_{k k}^{*} / c^{\prime \prime}+\bar{r}^{2}}
\end{aligned}
$$

The time paths for $\ln k$ and $\ln G$ are respectively:

$$
\begin{aligned}
& \ln k=\left(1-\mathrm{e}^{-\beta t}\right) \ln k^{*}+\mathrm{e}^{-\beta t} \ln k_{0} \\
& \ln G=\left(1-\mathrm{e}^{-\beta t}\right) \ln G^{*}+\mathrm{e}^{-\beta t} \ln G_{0}
\end{aligned}
$$

Thus, for any $t \geq 0, \ln k$ is a weighted average of the initial and steady state values, $\ln k_{0}$ and $\ln k^{*}$, with the weight on the initial value declining exponentially at the rate $\beta$. To differentiate the $\beta$-convergence speed with respect to the tax rate, we get

$$
\frac{\partial \beta}{\partial \bar{\tau}}=-\frac{1}{c^{\prime \prime}} k^{*} \frac{f_{G k}^{*}}{\sqrt{\bar{r}^{2}-4 \bar{\tau} k^{* *} f_{G k}^{*} / c^{\prime \prime}-4 k^{*} f_{k k}^{*} / c^{\prime \prime}}}
$$

Hence:

Proposition 2. If private and public capital are independent, the economic convergence speed is not affected by the fiscal policy setting; Providing that they are complements, a permanent increase in the capital tax rate reduces the economic convergence speed, i.e., $\operatorname{sgn}(\partial \beta / \partial \bar{\tau})=-\operatorname{sgn}\left(f_{G k}^{*}\right)$

Empirical evidence concurs that the two types of capital are complements and hence for policy makers looking raise taxation a longer period of transition can be expected. Meanwhile our model also suggests that governments finding themselves with a marginal product of public capital above 1 can not only enact a low tax, high infrastructure regime, but will see that achieved quicker.

${ }^{8}$ The advantage of the log-linearization method is to get a closed-form solution of the convergence coefficient. The disadvantage is that it applies only as an approximation around the steady state. 


\section{A Cobb-Douglas Economy}

By assuming that the production function is locally well approximated by a Cobb-Douglas function of one immobile factor-labour, and two imperfectly mobile factors-public and private capital, we can further motivate the theoretical discussion. Proportions are fixed at $0.2,0.7$ and 0.1 for private capital, labour and public capital respectively. China's GDP and tax revenue data suggests $\bar{\tau}=0.3$, but this is large compared to U.S. data ${ }^{9}$. For convenience we add $k^{*}=1$ and $\bar{r}=0.03^{10}$.

When relevant parameter values are specified, we calculate numerically the values of the derivatives in Equations (20)-(23). Figure 1 plots the values of the derivatives of factor stocks and their market values with respect to a fiscal policy parameter-capital tax rate, which indicates the comparative dynamic response to an increase in the fiscal burden on capital for both the baseline values of capital adjustment cost parameter $\left(c_{1}^{\prime \prime}=1 \text { and } c_{1}^{\prime \prime}=5\right)^{11}$. The figure shows clearly that the stock of private capital falls while the stock of public investment rises with an increase in the net capital tax in the long run. Comparatively, the market value of both private capital and public investment will fall contemporaneously with an increase in net capital taxation. But the market value of private capital does not fall monotonically to its new steady state. We can also observe that the adjustment in factor stocks takes a longer time than their market values although most responses occur within 25 years of a policy change. Comparing the pairs of dotted lines with the solid ones, it is shown that the lower the adjustment cost, the larger the speed of adjustment of the system. In such scenarios there is less incentive to defer adjustment to policy changes.

Discussions on factor return rates are equally important in the model and are of greater economic interest for policy makers. If the economy is assumed to start in a steady state with the same set of parameter values, we may compute the paths of $f_{k}, f_{G}$, and $w$, resp., denoting the gross return rates to private capital, public investment and labor. If the immobile factor is interpreted as land, then $W$ may refer to the land return rate. Derived from Equation (4), Equation (8) and Equation (10), the time paths of change in gross return rate in factor in response to a change in capital tax are given by:

$$
\frac{\mathrm{d} f_{k}}{\mathrm{~d} \bar{\tau}}=1+\bar{r} \frac{\mathrm{d} q_{1}}{\mathrm{~d} \bar{\tau}}, \frac{\mathrm{d} f_{G}}{\mathrm{~d} \bar{\tau}}=\bar{r} \frac{\mathrm{d} q_{2}}{\mathrm{~d} \bar{\tau}} \text { and } \frac{\mathrm{d} w}{\mathrm{~d} \bar{\tau}}=-k \frac{\mathrm{d} f_{k}}{\mathrm{~d} \bar{\tau}}-G \frac{\mathrm{d} f_{G}}{\mathrm{~d} \bar{\tau}}
$$

Given the assumed parameter values, these expressions can be calculated numerically using Equation (22) and Equation (23).

Figure 2 presents the transitional effect of the policy change in the gross return rates of private capital, public infrastructure investment and labour, which ${ }^{9}$ These figures can be adapted to different circumstances corresponding to fiscal systems for difference levels of governments in different nations at different periods of time.

${ }^{10}$ The choice of an interest rate $r$ amounts essentially to the choice of unit of time.

${ }^{11} c_{1}^{\prime \prime}=1$ and $c_{1}^{\prime \prime}=5$ as plausible baseline values in the absence of firmly-established empirical estimates for such parameters, roughly in accordance with empirical findings on the speed of adjustment of capital stocks, as discussed, e.g. in [46]. 


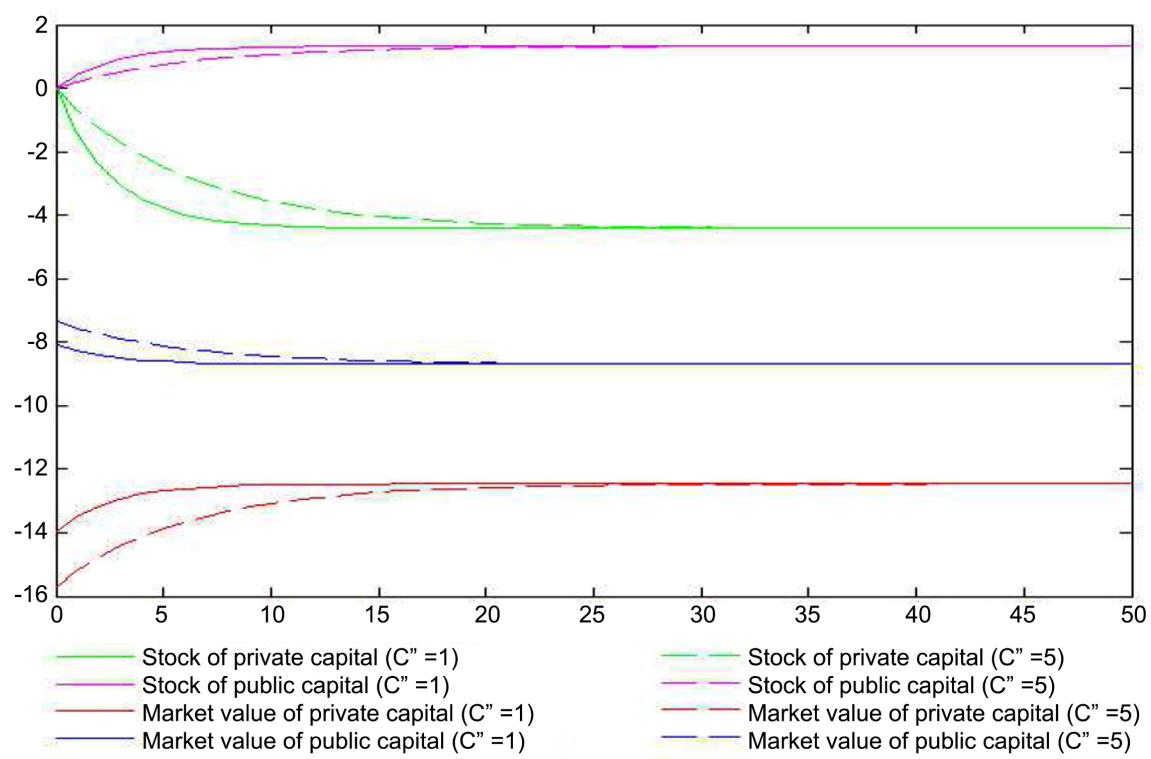

Figure 1. Dynamic effects of capital tax increase on factor stocks and market values.

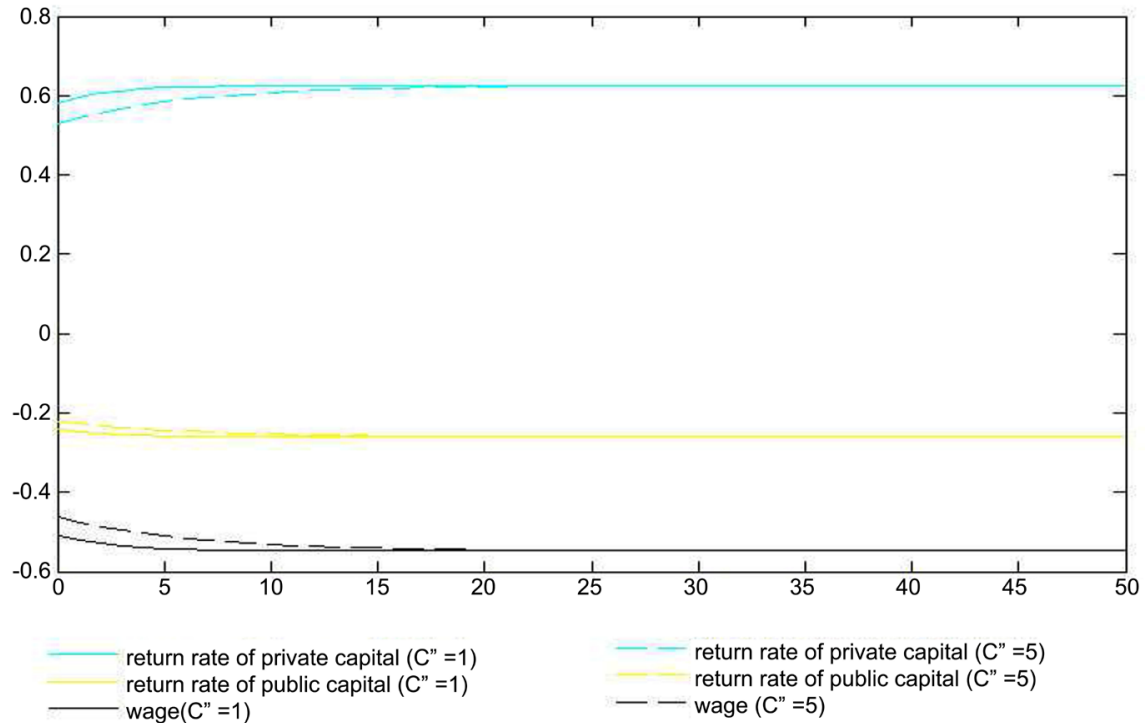

Figure 2. Dynamic effects of capital tax increase on factor return rates.

cannot occur in static models, retaining the baseline value for all $\left(c_{1}^{\prime \prime}=1\right.$ and $\left.c_{1}^{\prime \prime}=5\right)$. The return rates of public investment and labour both suffer a reduction that persists for some years corresponding to a rise in the capital tax rate, though the response of gross return rate of private capital to the policy change is positive. Similarly, the return to the long-run level factor return rate is much faster when the assumed cost of adjustment is lower.

Utilising different parameter values produces intuitively similar results, but with the speeds of adjustment and hence precise role of dynamic analysis being varied. Exploiting the dynamic framework allows a consideration of the convexity of the adjustment cost function for each factor, more convex forms meaning more protracted adjustment to changes in fiscal treatment. However, the transi- 
tion process still remains in all cases and its study remains of great importance to policy makers. To optimise use of our framework attention must be given to the likely convexity as well as the precise calibration and policy environment of the model. From the above we do now have a simple visualisation of the processes discussed in the analytical sections, and a footing on which further empirical work could grow.

\section{Concluding Remarks}

In a world classified by the rival forces of promoting inward investment and balancing budgets we see low capital taxes, high infrastructure spending and nations not borrowing to fund this. Extending static fiscal competition models after ZMW we show a dynamic framework in which precisely the observed pattern emerges in the set of equilibria. Key to enabling taxation to be imposed without deterring private capital is that public capital be sufficiently productive and there be a substitutability between the two sources. By detaching the direct link between private capital and its taxation rate many of the original results from the static literature are revisited. Dynamic models also enable us to show adjustment speeds and offer valuable insight to policymakers evaluating their taxation rates in light of the possible gains identified above. For the Cobb-Douglas economy much of the change was within one economic cycle, suggesting that incumbent governments may see the benefits on their own watch. Meanwhile, should public capital be less productive we move back to the initial two period results, but now with dynamic motivation.

In order to achieve high infrastructure spending at the same time as having low capital taxation, another factor must pay the price-immobile labour, or land. Despite open borders in the EU and elsewhere it is still true that migration percentages are low and this shift of the tax burden looks sustainable. Nations can continue to compete themselves further into this problem, or harmonise rates in regions. Advantages to labour of this are clear, but individual governments motivations to attract capital inflow remain stronger. Opening up the possibility of borrowing to fund investment would allow taxation on sticky factors to fall, but goes against the austerity mood. Consequently our dynamic extension, and consideration of infrastructure spending, provides a clear recreation of observed practice and reacquaints the fiscal competition literature with policy agendas. Further by exploring investments carefully our set up shows that a race to the top can be achieved, something leaders will inevitably be keen upon. Many significant policy implications thus result.

Many economists extol the virtues of increasing infrastructure to provide a platform for growth, and support for borrowing is strong. Shifting the burden from labour is appealing but may have consequences for future generations to meet this debt. Extending our framework to permit borrowing will thus be informative to the austerity debate, and illustrate under what circumstances higher output can be created than current legislation permits. However, by reflecting 
the contemporary global climate, and from the associated tractability of balanced budgets, we are able to contribute greatly to the discussion as is. Our Cobb-Douglas economy is only the tip of an explanatory iceberg, and scope exists for calibration of these illustrative cases. Through so doing a stronger message might be conveyed in terms of what fiscal policy might achieve and what benefits regional harmonisation might bring. In all sense the transition to dynamic framework will prove a vital stepping stone, and our model a strong foundation on which to build.

\section{Acknowledgements}

We sincerely acknowledge the funding support RDF-13-03-07 and RDF-14-03-19 from Xi'an Jiaotong-Liverpool University.

\section{Conflicts of Interest}

The authors declare no conflicts of interest regarding the publication of this paper.

\section{References}

[1] Zodrow, G.R. and Mieszkowski, P. (1986) Pigou, Tiebout, Property Taxation, and the Underprovision of Local Public Goods. Journal of Urban Economics, 19, 356-370.

[2] Wilson, J.D. (1986) A Theory of Interregional Tax Competition. Journal of Urban Economics, 19, 296-315.

[3] Kessler, A.S. and Lülfesmann, C. and Myers, G.M. (2002) Redistribution, Fiscal Competition, and the Politics of Economic Integration. The Review of Economic Studies, 69, 899-923. https://doi.org/10.1111/1467-937X.00230

[4] Aronsson, T., Micheletto, L. and Sjögren, T. (2014) A Note on Public Goods in a Decentralized Fiscal Union: Implications of a Participation Constraint. Journal of Urban Economics, 84, 1-8.

[5] Keuschnigg, C., Loretz, S. and Winner, H. (2014) Tax Competition and Tax Coordination in the European Union: A Survey. Department of Economics, University of St. Gallen.

[6] Oates, W.E. (2001) Fiscal Competition and European Union: Contrasting Perspectives. Regional Science and Urban Economics, 31, 133-145.

[7] Kanbur, R. and Keen, M. (1993) Jeux Sans Frontiers: Tax Competition and Tax Coordination When Countries Differ in Size. The American Economic Review, 83, 877-892.

[8] Wilson, J.D. (1999) Theories of Tax Competition. National Tax Journal, 52, 269-304.

[9] Wilson, J.D. and Wildasin, D.E. (2004) Capital Tax Competition: Bane or Boon. Journal of Public Economics, 88, 1065-1091.

[10] Slemrod, J. (2004) Are Corporate Tax Rates, or Countries, Converging? Journal of Public Economics, 88, 1169-1186.

[11] Pereira, A.M. and Andraz, J.M. (2013) On the Economic Effects of Public Infrastructure Investment: A Survey of the International Evidence. Journal of Economic 
Development, 38, 1-37.

[12] Tamai, T. (2008) A Note on the Dynamic Analysis of Fiscal Competition. Urban Studies, 45, 651-657. https://doi.org/10.1177/0042098007087339

[13] Becker, J. and Runkel, M. (2012) Even Small Trade Costs Restore Efficiency in Tax Competition. Journal of Urban Economics, 72, 191-195.

[14] Parry, I.W.H. (2003) How Large Are the Welfare Costs of Tax Competition? Journal of Urban Economics, 54, 39-60.

[15] Hauptmeier, S., Mittermaier, F. and Rincke, J. (2012) Fiscal Competition over Taxes and Public Inputs. Regional Science and Urban Economics, 42, 407-419.

[16] Justman, M., Thisse, J.-F. and Van Ypersele, T. (2005) Fiscal Competition and Regional Differentiation. Regional Science and Urban Economics, 35, 848-861. https://doi.org/10.1016/j.regsciurbeco.2005.04.001

[17] Makris, M. (2005) Dynamic Capital Tax Competition. Mimeo, Presented in Barcelona, IEB-Workshop on Fiscal Federalism.

[18] Klein, P. and Makris, M. (2014) Dynamic Capital Tax Competition.

[19] Keen, M. and Marchand, M. (1997) Fiscal Competition and the Pattern of Public Spending. Journal of Public Economics, 66, 33-53. https://doi.org/10.1016/S0047-2727(97)00035-2

[20] King, I., Preston, M.R. and Welling, L. (1993) Industrial Blackmail: Dynamic Tax Competition and Public Investment. Canadian Journal of Economics, 26, 590-608.

[21] Bellak, C., Leibrecht, M. and Damijan, J.P. (2009) Infrastructure Endowment and Corporate Income Taxes as Determinants of Foreign Direct Investment in Central and Eastern European Countries. The World Economy, 32, 267-290. https://doi.org/10.1111/j.1467-9701.2008.01144.x

[22] Munnell, A.H. (1992) Policy Watch: Infrastructure Investment and Economic Growth. The Journal of Economic Perspectives, 6, 189-198. https://doi.org/10.1257/jep.6.4.189

[23] Martin, P. and Rogers, C.A. (1995) Industrial Location and Public Infrastructure. Journal of International Economics, 39, 335-351. https://doi.org/10.1016/0022-1996(95)01376-6

[24] Van der Velde, M. and van Naerssen, T. (2011) People, Borders, Trajectories: An Approach to Cross-Border Mobility and Immobility in and to the European Union. Area, 43, 218-224. https://doi.org/10.1111/j.1475-4762.2010.00974.x

[25] Josifidis, K., Supic, N., Pucar, E.B. and Srdic, S. (2014) Labour Migration Flows: EU8 + 2 vs. EU15. Journal of Business Economics and Management, 15, 41-55. https://doi.org/10.3846/16111699.2013.841283

[26] Wagner, I. (2015) The Political Economy of Borders in a "Borderless" European Labour Market. JCMS: Journal of Common Market Studies, 53, 1370-1385.

[27] Treasury, H.M. (2013) Planning for Economic Infrastructure. National Audit Office.

[28] Agénor, P.-R. and Yilmaz, S.D. (2011) The Tyranny of Rules: Fiscal Discipline, Productive Spending, and Growth in a Perfect Foresight Model. Journal of Economic Policy Reform, 14, 69-99. https://doi.org/10.1080/17487870.2010.503086

[29] Breunig, C. and Busemeyer, M.R. (2012) Fiscal Austerity and the Trade-Off between Public Investment and Social Spending. Journal of European Public Policy, 19, 921-938. https://doi.org/10.1080/13501763.2011.614158

[30] Chong, S., Poole, E., et al. (2013) Financing Infrastructure: A Spectrum of Country 
Approaches. RBA Bulletin, Reserve Bank of Australia, 65-76.

[31] Kehoe, P.J. (1989) Policy Cooperation among Benevolent Governments May Be Undesirable. Review of Economic Studies, 56, 289-296.

https://doi.org/10.2307/2297462

[32] Jensen, R. and Toma, E.F. (1991) Debt in a Model of Tax Competition. Regional Science and Urban Economics, 21, 371-392. https://doi.org/10.1016/0166-0462(91)90064-T

[33] Hercowitz, Z. and Pines, D. (1991) Migration with Fiscal Externalities. Journal of Public Economics, 46, 163-180. https://doi.org/10.1016/0047-2727(91)90002-J

[34] Wildasin, D.E. and Wilson, J.D. (1996) Imperfect Mobility and Local Government Behaviour in an Overlapping-Generations Model. Journal of Public Economics, 60, 177-198. https://doi.org/10.1016/0047-2727(95)01533-7

[35] Walz, U. and Wellisch, D. (1996) Strategic Provision of Local Public Inputs for Oligopolistic Firms in the Presence of Endogenous Location Choice. International Tax and Public Finance, 3, 175-189. https://doi.org/10.1007/BF00399909

[36] Wildasin, D.E. (2003) Fiscal Competition in Space and Time. Journal of Public Economics, 87, 2571-2588. https://doi.org/10.1016/S0047-2727(02)00055-5

[37] Wildasin, D.E. (2011) Fiscal Competition for Imperfectly-Mobile Labor and Capital: A Comparative Dynamic Analysis. Journal of Public Economics, 95, 1312-1321. https://doi.org/10.1016/j.jpubeco.2010.11.014

[38] Ogawa, H., Sato, Y. and Tamai, T. (2006) A Note on Unemployment and Capital Tax Competition. Journal of Urban Economics, 60, 350-356. https://doi.org/10.1016/j.jue.2005.07.002

[39] Tobin, J. (1969) A General Equilibrium Approach to Monetary Theory. Journal of Money, Credit \& Banking, 1, 15-29. https://doi.org/10.2307/1991374

[40] Boadway, R. (1979) Long-Run Tax Incidence: A Comparative Dynamic Approach. The Review of Economic Studies, 46, 505-511. https://doi.org/10.2307/2297016

[41] Gandolfo, G. (1996) Economic Dynamics. Springer Verlag, Berlin.

[42] Aschauer, D.A. (1989) Does Public Capital Crowd out Private Capital? Journal of Monetary Economics, 24, 171-188. https://doi.org/10.1016/0304-3932(89)90002-0

[43] Aschauer, D.A. (1989) Is Public Expenditure Productive? Journal of Monetary Economics, 23, 177-200. https://doi.org/10.1016/0304-3932(89)90047-0

[44] Pereira, A.M. (2000) Is All Public Capital Created Equal? Review of Economics \& Statistics, 82, 513. https://doi.org/10.1162/rest.2000.82.3.513

[45] Barro, R.J. and Sala-i-Martin, X. (2003) Economic Growth. The MIT Press, Cambridge.

[46] Shapiro, M.D. (1986) The Dynamic Demand for Capital and Labor. The Quarterly Journal of Economics, 101, 513-542. https://doi.org/10.2307/1885695 


\section{Appendix A. Derivation of Equations (3)-(6)}

Define the Hamiltonian of the dynamic optimization problem in Section 2.

$$
H=\{f(k, G)-w-(\bar{r}+\bar{\tau}) k-[i+c(i)] k\} \mathrm{e}^{-\bar{r} t}+v_{1} \dot{k}+v_{2} \dot{G}
$$

where $v_{1}$ and $v_{2}$ denote the co-state variables associated with the state variables $k$ and $G$. The transversality condition is

$$
\lim _{t \rightarrow \infty} v_{1} k=0 \text { and } \lim _{t \rightarrow \infty} v_{2} G=0 .
$$

The current value Hamiltonian is

$$
H^{c}=f(k, G)-w-(\bar{r}+\bar{\tau}) k-i k-k c(i)+q_{1}(i-\bar{\delta}) k+q_{2} \bar{\tau}(i-\bar{\delta}) k
$$

where $q_{1}=v_{1} \mathrm{e}^{\overline{r t}}$, and $q_{2}=v_{2} \mathrm{e}^{\overline{r t}}$.

The necessary conditions of the Hamiltonian System are:

$$
\begin{gathered}
\frac{\partial H^{c}}{\partial i}=0, \frac{\partial^{2} H^{c}}{\partial i^{2}}=-c^{\prime \prime}(i)<0 \\
w=f(k, G)-f_{k} k-f_{G} G \\
\dot{q}_{1}=-\frac{\partial H^{c}}{\partial k}+\bar{r} q_{1} \\
\dot{q}_{2}=-\frac{\partial H^{c}}{\partial G}+\bar{r} q_{2}
\end{gathered}
$$

Solving from Equations (A.3)-(A.6), produces Equations (3)-(6).

\section{Appendix B. The Method of Variational Equations and Derivation of Equation (14)}

In Section 3, the state of the system depends on the capital stock $k$, the public input stock $G$ and their shadow values. Differentiation of Equations (7) to (10) assuming that the system is initially in equilibrium gives four first-order differential equations in

$$
\left(\mathrm{d} k_{t} / \mathrm{d} \bar{\tau}, \mathrm{d} q_{1 t} / \mathrm{d} \bar{\tau}, \mathrm{d} q_{2 t} / \mathrm{d} \bar{\tau}, \mathrm{d} G_{t} / \mathrm{d} \bar{\tau}\right)
$$

with respect to time $t$,

$$
\left(\begin{array}{c}
\mathrm{d} \dot{k} / \mathrm{d} \bar{\tau} \\
\mathrm{d} \dot{q}_{1} / \mathrm{d} \bar{\tau} \\
\mathrm{d} \dot{G} / \mathrm{d} \bar{\tau} \\
\mathrm{d} \dot{q}_{2} / \mathrm{d} \bar{\tau}
\end{array}\right)=\left(\begin{array}{cccc}
\partial \dot{k} / \partial k & \partial \dot{k} / \partial q_{1} & \partial \dot{k} / \partial G & \partial \dot{k} / \partial q_{2} \\
\partial \dot{q}_{1} / \partial k & \partial \dot{q}_{1} / \partial q_{1} & \partial \dot{q}_{1} / \partial G & \partial \dot{q}_{1} / \partial q_{2} \\
\partial \dot{G} / \partial k & \partial \dot{G} / \partial q_{1} & \partial \dot{G} / \partial G & \partial \dot{G} / \partial q_{2} \\
\partial \dot{q}_{2} / \partial k & \partial \dot{q}_{2} / \partial q_{1} & \partial \dot{q}_{2} / \partial G & \partial \dot{q}_{2} / \partial q_{2}
\end{array}\right)\left(\begin{array}{c}
\mathrm{d} k / \mathrm{d} \bar{\tau} \\
\mathrm{d} q_{1} / \mathrm{d} \bar{\tau} \\
\mathrm{d} G / \mathrm{d} \bar{\tau} \\
\mathrm{d} q_{2} / \mathrm{d} \bar{\tau}
\end{array}\right)+\left(\begin{array}{c}
\partial \dot{k} / \partial \bar{\tau} \\
\partial \dot{q}_{1} / \partial \bar{\tau} \\
\partial \dot{G} / \partial \bar{\tau} \\
\partial \dot{q}_{2} / \partial \bar{\tau}
\end{array}\right)
$$

To differentiate Equation (7), with respect to $\left(k, q_{1}, G, q_{2}\right)$, we get

$$
\left[\begin{array}{c}
\partial \dot{k} / \partial k \\
\partial \dot{k} / \partial q_{1} \\
\partial \dot{k} / \partial G \\
\partial \dot{k} / \partial q_{2}
\end{array}\right]=\left[\begin{array}{c}
\phi\left(q_{1}, q_{2}\right)-\bar{\delta} \\
k \phi_{1} \\
0 \\
k \phi_{2}
\end{array}\right]
$$

To differentiate Equation (8), with respect to $\left(k, q_{1}, G, q_{2}\right)$, we get 


$$
\left[\begin{array}{c}
\partial \dot{q}_{1} / \partial k \\
\partial \dot{q}_{1} / \partial q_{1} \\
\partial \dot{q}_{1} / \partial G \\
\partial \dot{q}_{1} / \partial q_{2}
\end{array}\right]=\left[\begin{array}{c}
-f_{k k} \\
\bar{r}+\delta-\phi+\left(1+c^{\prime}-q_{1}-q_{2} \bar{\tau}\right) \phi_{1} \\
-f_{k G} \\
\left(1+c^{\prime}-q_{1}-q_{2} \bar{\tau}\right) \phi_{2}-\bar{\tau}(i-\bar{\delta})
\end{array}\right]
$$

To differentiate Equation (9), with respect to $\left(k, q_{1}, G, q_{2}\right)$, we get

$$
\left[\begin{array}{c}
\partial \dot{G} / \partial k \\
\partial \dot{G} / \partial q_{1} \\
\partial \dot{G} / \partial G \\
\partial \dot{G} / \partial q_{2}
\end{array}\right]=\left[\begin{array}{c}
\bar{\tau}(i-\bar{\delta}) \\
\bar{\tau} k \phi_{1} \\
0 \\
\bar{\tau} k \phi_{2}
\end{array}\right]
$$

To differentiate Equation (10), with respect to $\left(k, q_{1}, G, q_{2}\right)$, we get

$$
\left[\begin{array}{c}
\partial \dot{q}_{2} / \partial k \\
\partial \dot{q}_{2} / \partial q_{1} \\
\partial \dot{q}_{2} / \partial G \\
\partial \dot{q}_{2} / \partial q_{2}
\end{array}\right]=\left[\begin{array}{c}
-f_{k G} \\
0 \\
-f_{G G} \\
\bar{r}
\end{array}\right]
$$

Using the method of variational equations introduced above, with

$$
c^{\prime \prime} \phi_{1}^{\prime}=1, c^{\prime \prime} \phi_{2}^{\prime}=\bar{\tau}, q_{2}=c^{\prime \prime} \phi_{\bar{\tau}}^{\prime},
$$

and substituting the steady-state values expressed in Equations (11)-(13), into Equation (B.1), we then get Equation (14).

\section{Appendix C. Derivation of Equations (20)-(23)}

The general solution to the dynamic system (15) can be expressed as

$$
\left[\begin{array}{c}
\mathrm{d} k / \mathrm{d} \bar{\tau} \\
\mathrm{d} q_{1} / \mathrm{d} \bar{\tau} \\
\mathrm{d} q_{2} / \mathrm{d} \bar{\tau}
\end{array}\right]=\left[\begin{array}{ccc}
A_{1} \alpha_{1}^{(1)} & A_{2} \alpha_{1}^{(2)} & A_{3} \alpha_{1}^{(3)} \\
A_{1} \alpha_{2}^{(1)} & A_{2} \alpha_{2}^{(2)} & A_{3} \alpha_{2}^{(3)} \\
A_{1} \alpha_{3}^{(1)} & A_{2} \alpha_{3}^{(2)} & A_{3} \alpha_{3}^{(3)}
\end{array}\right]\left[\begin{array}{l}
\mathrm{e}^{\lambda_{1} t} \\
\mathrm{e}^{\lambda_{2} t} \\
\mathrm{e}^{\lambda_{3} t}
\end{array}\right]+\left[\begin{array}{l}
\mathrm{d} k^{*} / \mathrm{d} \bar{\tau} \\
\mathrm{d} q_{1}^{*} / \mathrm{d} \bar{\tau} \\
\mathrm{d} q_{2}^{*} / \mathrm{d} \bar{\tau}
\end{array}\right]
$$

where $a^{(1)}, a^{(2)}, a^{(3)}$ are the column eigenvectors corresponding to above eigenvalues $\lambda_{1}, \lambda_{2}$ and $\lambda_{3} \cdot \mathrm{d} k^{*} / \mathrm{d} \bar{\tau}, \mathrm{d} q_{1}^{*} / \mathrm{d} \bar{\tau}$ and $\mathrm{d} q_{2}^{*} / \mathrm{d} \bar{\tau}$ are the particular solutions to the dynamic system (15), i.e., the steady state equilibrium values in the long run. Through manipulation and calculation,

$$
\begin{aligned}
\left(a^{(1)}, a^{(2)}, a^{(3)}\right) & =\left[\begin{array}{ccc}
0 & \lambda_{3} / f_{G k}^{*} & \lambda_{2} / f_{G k}^{*} \\
-\bar{\tau} & f_{k k}^{*} / f_{G k}^{*} & f_{k k}^{*} / f_{G k}^{*} \\
1 & 1 & 1
\end{array}\right] \\
{\left[\begin{array}{c}
\mathrm{d} k^{*} / \mathrm{d} \bar{\tau} \\
\mathrm{d} q_{1}^{*} / \mathrm{d} \bar{\tau} \\
\mathrm{d} q_{2}^{*} / \mathrm{d} \bar{\tau}
\end{array}\right] } & =\left[\begin{array}{c}
\frac{1-f_{G}^{*}}{\bar{\tau} f_{G k}^{*}+f_{k k}^{*}} \\
\frac{(-\bar{\tau}) f_{G k}^{*}-f_{G}^{*} f_{k k}^{*}}{\bar{r} \bar{\tau} f_{G k}^{*}+\bar{r} f_{k k}^{*}} \\
\frac{f_{G k}^{*}-f_{G}^{*} f_{G k}^{*}}{\bar{r} \bar{\tau} f_{G k}^{*}+\bar{r} f_{k k}^{*}}
\end{array}\right]
\end{aligned}
$$

Equation (C.1) therefore changes to 


$$
\left[\begin{array}{c}
\mathrm{d} k / \mathrm{d} \bar{\tau} \\
\mathrm{d} q_{1} / \mathrm{d} \bar{\tau} \\
\mathrm{d} q_{2} / \mathrm{d} \bar{\tau}
\end{array}\right]=\left[\begin{array}{ccc}
0 & A_{2} \lambda_{3} / f_{G k}^{*} & A_{3} \lambda_{2} / f_{G k}^{*} \\
A_{1}(-\bar{\tau}) & A_{2} f_{k k}^{*} / f_{G k}^{*} & A_{3} f_{k k}^{*} / f_{G k}^{*} \\
A_{1} & A_{2} & A_{3}
\end{array}\right]\left[\begin{array}{c}
\mathrm{e}^{\lambda_{1} t} \\
\mathrm{e}^{\lambda_{2} t} \\
\mathrm{e}^{\lambda_{3} t}
\end{array}\right]+\left[\begin{array}{c}
\frac{1-f_{G}^{*}}{\bar{\tau} f_{G k}^{*}+f_{k k}^{*}} \\
\frac{(-\bar{\tau}) f_{G k}^{*}-f_{G}^{*} f_{k k}^{*}}{\bar{r} \bar{\tau} f_{G k}^{*}+\bar{r} f_{k k}^{*}} \\
\frac{f_{G k}^{*}-f_{G}^{*} f_{G k}^{*}}{\bar{r} \bar{\tau} f_{G k}^{*}+\bar{r} f_{k k}^{*}}
\end{array}\right]
$$

Substituting boundary conditions $\mathrm{d} k_{0} / \mathrm{d} \bar{\tau}=0$, and $\lim _{t \rightarrow \infty} \mathrm{d} k(t) / \mathrm{d} \bar{\tau}=\mathrm{d} k^{*} / \mathrm{d} \bar{\tau}$ into Equation (C.4), it can be derived that

$$
\begin{aligned}
& A_{1}=0 \\
& A_{2}=-\frac{f_{G k}^{*}\left(1-f_{G}^{*}\right)}{\lambda_{3}\left(\bar{\tau} f_{G k}^{*}+f_{k k}^{*}\right)} \\
& A_{3}=0
\end{aligned}
$$

Given $A_{1}, A_{2}$ and $A_{3}$, the solutions to the dynamic system, that is, Equations (20) to (23) are obtained. 